\title{
Programa de melhoria da proficiência e a formação continuada de professores que ensinam Matemática na Rede Municipal de Cuiabá
}

\author{
Proficiency improvement program and continuing education for teachers who teach Mathematics \\ in the Municipality of Cuiaba
}

Programa de mejoramiento de la competencia y educación continua para docentes que enseñan Matemática en el Municipio de Cuiabá

Recebido: 20/05/2021 | Revisado: 26/05/2021 | Aceito: 01/06/2021 | Publicado: 14/06/2021

\author{
Cecília Batista Duarte Campos \\ ORCID: https://orcid.org/0000-0003-3248-1331 \\ Universidade de Cuiabá, Brasil \\ E-mail: professoraceciliaduarte@gmail.com \\ Elizaine Vaz Santos \\ ORCID: https://orcid.org/0000-0001-6164-3155 \\ Universidade de Cuiabá, Brasil \\ E-mail: elizaine.vaz@gmail.com \\ Laura Isabel Marques Vasconcelos de Almeida \\ ORCID: https://orcid.org/0000-0003-3973-7408 \\ Universidade de Cuiabá, Brasil \\ E-mail: lauraisabelvasc@ hotmail.com \\ Maria Helena da Silva \\ ORCID: https://orcid.org/0000-0002-4374-6385 \\ Universidade de Cuiabá, Brasil \\ E-mail: freitashelen@yahoo.com.br
}

\begin{abstract}
Resumo
$\mathrm{O}$ artigo retrata as reflexões sobre a experiência vivenciada durante a formação continuada de professores dos anos iniciais da rede municipal de Cuiabá, no período de isolamento social, devido à pandemia da Covid19. Tem como objetivo socializar o processo de formação no ambiente virtual, com ênfase nas contribuições desse novo normal para o desenvolvimento do processo de ensino e aprendizagem de matemática. A metodologia com abordagem qualitativa centra-se como uma investigação de forma continuada, sistemática e empiricamente, fundamentada com a finalidade de aprimorar a prática docente. O relato evidencia a formação desenvolvida pelos professores que ministram aulas de matemática na rede municipal no $4^{\circ}$ ano do ensino fundamental, concebendo-os como sujeitos do processo de formação, que tiveram que se adaptar e reinventar em sala de aula no ensino remoto. Diante do estudo realizado pode se inferir que os desafios vivenciados pelos professores neste cenário atípico estão mais relacionados às dificuldades ao uso das novas tecnologias, bem como, a necessidade da transposição da teoria para prática, pois nota-se que os discursos teóricos estão avançados, quando se trata da construção de visão crítica da educação e da realidade do ensino, entretanto, o que se observa são práticas ainda arraigadas e cristalizadas, consideradas tradicionais, pautadas na transmissão do conhecimento e, consequentemente, a dificuldade de trabalhar com as ferramentas digitais.
\end{abstract}

Palavras-chave: Formação continuada; Ensino remoto; Ensino de matemática.

\begin{abstract}
The article portrays the reflections on the experience lived during the continuing education of teachers of the initial years of the municipal network of Cuiabá, in the period of social isolation, due to the pandemic of Covid19. It aims to socialize the training process in the virtual environment, with an emphasis on the contributions of this new normal to the development of the mathematics teaching and learning process. The methodology with a qualitative approach focuses as an investigation in a continuous, systematic and empirical way, grounded with the purpose of improving the teaching practice. The report shows the training developed by teachers who teach mathematics classes in the municipal system in the 4th year of elementary school, conceiving them as subjects of the training process, who had to adapt and reinvent themselves in the classroom in remote education. Given the study carried out, it can be inferred that the challenges experienced by teachers in this atypical scenario are more related to the difficulties in the use of new technologies, as well as the need to translate theory into practice, as it is noted that the theoretical speeches are advanced, when it comes to the construction of a critical view of education and the reality of teaching, however, what is observed are practices that are still ingrained and crystallized, considered traditional, based on the transmission of knowledge and, consequently, the difficulty of working with digital tools.
\end{abstract}


Keywords: Continuing education; Remote teaching; Mathematics teaching.

\section{Resumen}

El artículo retrata las reflexiones sobre la experiencia vivida durante la formación continuada de los docentes de los primeros años de la red municipal de Cuiabá, en el período de aislamiento social, debido a la pandemia de Covid19. Tiene como objetivo socializar el proceso de formación en el entorno virtual, con énfasis en los aportes de esta nueva normalidad al desarrollo del proceso de enseñanza y aprendizaje de las matemáticas. La metodología con enfoque cualitativo se enfoca como una investigación de manera continua, sistemática y empírica, fundamentada con el propósito de mejorar la práctica docente. El informe muestra la formación desarrollada por los docentes que imparten clases de matemáticas en el sistema municipal en el $4^{\circ}$ año de la escuela primaria, concibiéndolas como sujetos del proceso formativo, que debían adaptarse y reinventarse en el aula en educación remota. A la vista del estudio realizado, se puede inferir que los desafíos que experimentan los docentes en este escenario atípico están más relacionados con las dificultades en el uso de las nuevas tecnologías, así como con la necesidad de trasponer la teoría a la práctica, como se observa que los discursos teóricos son avanzados, cuando se trata de la construcción de una mirada crítica de la educación y la realidad de la enseñanza, sin embargo, lo que se observa son prácticas que aún están arraigadas y cristalizadas, consideradas tradicionales, basadas en la transmisión de conocimientos y, en consecuencia, la dificultad de trabajar con herramientas digitales.

Palabras clave: Educación continua; Enseñanza remota; Enseñanza de las matemáticas.

\section{Introdução}

Os movimentos para implantação da formação continuada vêm de tempos anteriores, quando pesquisadores começaram a perceber que havia necessidade desse processo visando a melhoria da prática docente. De acordo com os estudos de (Saviani, 2009, p.2) "o primeiro estabelecimento de ensino destinado à formação de professores teria sido instituído por São João Batista de La Salle em 1684, em Reims, com o nome de Seminário dos Mestres".

No Brasil, a valorização da formação continuada ocorre com a promulgação da Constituição Federal de 1988. A esse respeito, Aranha (1996) destaca como principais mudanças, gratuidade do ensino público em estabelecimentos oficiais em todos os níveis de ensino, ensino fundamental obrigatório, atendimento em creches e pré-escolas, valorização dos profissionais com planos de carreira para o magistério em instituições públicas.

A Constituição de 1988 trouxe muitas reflexões sobre o processo de ensino, que culminaram na promulgação da Lei de Diretrizes e Bases da Educação Nacional (LDB/96) - Lei nº 9.394 de 20 de dezembro de 1996, uma nova organização e regulamentação da estrutura e do funcionamento do sistema educacional em todo o país, inclusive a valorização dos profissionais de ensino, com oferta de programas de formação continuada.

A LDB/96 faz referência específica sobre a formação continuada dos professores, em seu Título VI, onde trata dos Profissionais da Educação, enfatizado no artigo 61, que a formação dos profissionais da educação deve ser realizada de maneira que atenda aos objetivos dos diferentes níveis e modalidades de ensino, bem como, as características peculiares de cada fase do desenvolvimento do educando, tendo como fundamento intrínseco a associação entre teoria e prática, inclusive mediante a capacitação em serviço, ocorrendo ainda, a articulação entre os cursos de formação inicial e diferentes programas de formação continuada.

Em Mato Grosso, o intento era construir uma escola democrática, de qualidade onde o estudante permanecesse tendo acesso gratuito e continuidade aos estudos, com ênfase no desenvolvimento humano e participativo. Apoiada na prática reflexiva e cidadã, confirmando o direito constitucional básico, o governo estadual elaborou por meio da Secretaria do Estado de Educação (SEDUC), o Projeto Político Pedagógico que buscasse atender a demanda e a realidade das unidades escolares com a finalidade de superar a fragmentação e diminuir o índice de repetência e evasão escolar. Nesta busca constante emerge a proposta de implantação dos Ciclos de Formação Humana, abrangendo as escolas públicas mato-grossenses de Ensino Fundamental, denominada de Escolas Cicladas de Mato Grosso, que posteriormente amplia-se para vários municípios.

O Projeto Pedagógico das escolas organizadas em Ciclos de formação já vinha sendo discutido e implantado nacionalmente e logo passou a ser instituído politicamente nas esferas estaduais e municipais. Neste contexto, Mato Grosso fez 
adesão a esse tipo de organização, onde o espaço e o tempo são considerados essenciais para o desenvolvimento humano, concebendo a educação e o currículo como um processo permanente em construção (Mato Grosso, 2001, p.20-25).

Tendo como base as prescrições oficiais, a Rede Municipal de Ensino de Cuiabá-MT inicia o debate sobre reestruturação curricular no final dos anos 80. No documento preliminar da política da Escola Sarã, a Secretaria Municipal de Educação de Cuiabá (SME) vem reestruturando as políticas pedagógicas desde 1986, apresentando como eixos "a universalização do atendimento escolar; construção de uma escola pública, democrática, autônoma, descentralizadora e participativa" (Cuiabá, 1999, p. 9).

Neste cenário, a partir de 1990, a Secretaria Municipal de Educação de Cuiabá (SME/CBA) passa a investir na formação continuada proporcionando aos profissionais da educação vários estudos e reflexões sobre formação docente e, posteriormente no ano de 1993, estabelece parcerias com instituições de ensino, visando à reorganização curricular das unidades de ensino municipal, resultando na implantação de cursos, encontros e seminários, onde foram abordados temas referentes às concepções teóricas de educação, currículo e as demais áreas do conhecimento (Cuiabá, 2020).

Inicialmente, as formações tinham como base os centros de interesse, denominado como "Tema Gerador " fundamentado nas ideias de Paulo Freire (1987) origina-se de um problema que envolve apreensão da realidade, análise, organização, e sistematização, originando programas de ensino a partir do diálogo.

O Tema Gerador parte da problematização (questões desafiadoras postas pela prática social), dúvidas, discussões e questionamentos dos conhecimentos e da realidade que se faz necessário dominar. Geradores porque "tem-se a possibilidade de desdobrar-se em outros tantos temas (eixos temáticos e subtemas) que, por sua vez, provocam novas tarefas que devem ser cumpridas" (Freire, 1987, p. 124).

Assim os temas das formações eram direcionados à reorganização curricular, planejamento globalizado, gestão democrática e avaliação, abrangendo e envolvendo os profissionais da educação com a participação dos atores educacionais, com a finalidade de definir as diretrizes político-pedagógicas da rede municipal de ensino (Cuiabá, 2020).

As concepções de Freire (1987) partem do estudo da realidade vivenciada pelos estudantes e da organização do educador, politização da ação educativa, presença de uma relação ampla, equilibrada de dialogicidade e, defronte a essas considerações, surgem os Temas Geradores, que por sua vez emergem das problematizações extraídas da vida e do contexto social dos educandos, ou seja, a realidade é a base temática que possibilitam diversas problemáticas, as quais proporcionam a inserção, compreensão e formação crítica do educando.

Com base nas concepções freiriana, a Rede Municipal de Ensino de Cuiabá passou por várias transformações que resultaram na implantação dos Ciclos de Formação Humana. Período que emergem várias produções e, no ano de 1998, a SME publica o primeiro livro "Projeto Saranzal" (primeira denominação) com as novas diretrizes político-pedagógicas do sistema educacional de ensino.

Em 1998, o Projeto Saranzal dá início as discussões sobre a mudança e transição da Escola Seriada para a Escola Ciclada tendo como perspectiva, a concepção de uma nova organização aos tempos e espaços escolares para a aprendizagem, considerada como uma meta fundamental, visando a inserção e formação de uma sociedade sem exclusão, voltada aos interesses da maioria (Cuiabá, 2019, p. 8).

Neste contexto de mudanças e ressignificações dos componentes curriculares, o Projeto Saranzal foi apresentado e discutido com representantes de todos os segmentos das unidades escolares e, a partir dos debates e trocas de experiências foi sendo lapidado, fundamentado e aos poucos transformando a política educacional da rede municipal de ensino, que posteriormente foi denominada de "Escola Sarã: Cuiabá nos Ciclos de Formação", publicado no ano de 2000.

A nova proposta teve uma preparação que antecede a publicação da obra. Neste período a SME possibilitou um estudo de dois anos consecutivos junto às equipes técnicas (Diretores, Supervisores escolares, Secretários) e professores das unidades 
escolares para conhecer e compreender a proposta, tendo como primeiro tema de grande repercussão a avaliação da aprendizagem.

No ano de 1999, a rede lança o livro "Uma nova avaliação para um novo contexto nas escolas municipais de Cuiabá" com o intuito de esclarecer as novas concepções sobre a avaliação para a prática cotidiana do professor em sala de aula. Neste interim, aprofundam-se as discussões e após a realização dos seminários promovidos pela entidade mantenedora acontece a segunda edição revisada e atualizada do livro, "Escola Sarã" com ênfase na formação de professores. Pautada na reflexão sobre a ação pedagógica e a socialização dessa reflexão, possibilitando a intervenção dialógica e crítica na prática pedagógica por meio da teorização (Cuiabá, 2000, p.87).

A Escola Sarã foi construída com a parceria e assessoria pedagógica dos docentes da Universidade Federal de Mato Grosso (UFMT) sendo consolidada considerando os princípios da gestão democrática, desmontando o modelo piramidal e delineando-se pela coletividade, afirmando o papel da escola para formação cidadã (Cuiabá, 2000, p.15-20).

Neste período a proposta da Escola Sarã contribuiu com inovação e ressignificação dos processos de elaboração curricular como uma nova forma de organização da escola e a gestão, considerando os tempos e espaços para aprender, trazendo como princípio democrático a garantia de um ensino de qualidade e uma aprendizagem significativa para todos (Cuiabá, 2019, p.24).

Em 2000, o ano letivo foi bastante produtivo, principalmente com a organização do Programa de Qualificação Docente, com base na "linha crítico-reflexiva da educação como uma prática social. Nesta linha, a escola é concebida, como local de formação permanente, uma vez que se constitui num movimento que exige a participação dos atores educacionais, numa ação contínua e interrogativa" (Cuiabá, 2000, p.87).

Observa-se que a política adotada pelos gestores do sistema da rede de ensino cuiabana, permanece associada ao pensamento freiriano, considera a prática e formação do estudante e docente, crítica, argumentativa relacionando o fazer e o pensar, gerando dinamicamente no educador uma permanente reflexão das suas ações, produzindo respostas, ações, e transformações de acordo com cada tempo histórico.

Ao longo do tempo, as discussões e formações internas se ampliaram e mais uma vez, a necessidade de adequar a proposta educacional da rede de ensino. Em 2017, considerando as discussões nacionais e estaduais da Base Nacional Comum Curricular (BNCC) os assessores, gestores, professores e profissionais da educação pertencentes à Secretaria Municipal de Educação, percebem a necessidade de propor uma nova abordagem e elaboração da proposta da rede municipal que valorize e considere a realidade local incluindo a diversidade étnica, com a inserção de povos originários, colonizadores, migrantes e imigrantes, os biomas da região, como o Cerrado, Pantanal e Amazônia, e outros elementos históricos, culturais e ambientais.

No ano de 2019, a Política Educacional da Rede Municipal de Ensino de Cuiabá é consolidada e torna-se uma realidade com a "Escola Cuiabana: cultura, tempos de vida, direitos de aprendizagem e inclusão". Trata-se de uma proposta diversificada que foi pensada e elaborada com os pares para direcionar o Projeto Político Pedagógico das unidades escolares e principalmente a formação continuada dos profissionais da educação do município de Cuiabá. Contempla uma ampla fundamentação teórica, sugere metodologias, projetos, formas e instrumentos de avaliação, com ênfase na proposta de organização dos estudantes em seus ciclos de vida: infância, adolescência, juventude, adulto e idoso, aprofundando a compreensão sobre o modo como cada etapa da vida pensa, aprende e socializa na sociedade contemporânea, midiática e continuamente conectada.

Pensando no Projeto educacional, a SME tem buscado efetivar políticas públicas e práticas pedagógicas que promovam melhorias dos índices de aprendizagem, redução da indisciplina, aumento da participação da família, formação integral dos estudantes, melhor qualidade de vida e do bem-estar psíquico de toda comunidade educacional. Com base nas demandas do século XXI, que partem de novos paradigmas, principalmente relacionados aos aspectos cognitivos, o uso das 
novas tecnologias e a educação emocional, considerando as habilidades a partir da BNCC e inserindo as especificidades de cada região (Brasil, 2017, p. 18-23).

O Letramento Digital apresenta-se como exigência aos sujeitos emersos nos contextos da era digital, em que a sociedade contemporânea está imersa nos contextos tecnológicos, tal fenômeno origina-se do processo de globalização ocorrido nas últimas décadas (Conceição \& Ghisleni, 2019, p. 3).

A Escola Cuiabana tem a finalidade de compartilhar metodologias que contribuam para o processo de inovação nas salas de aula que vão, por meio dos recursos tecnológicos, originando mais eficácia aos processos de aprendizagem (Cuiabá, 2020, p. 230-233). As concepções inerentes à proposta abordam o pensamento cientifico, cultural, digital, bem como, a aplicabilidade dos recursos para o ensino do professor e aprendizagem dos discentes em sala de aula. Ainda enfatiza a efetividade do conhecimento adquirido pelos profissionais que devem se colocar no papel de estudante experimentando diversos modelos didáticos, proporcionando o fortalecimento da aprendizagem.

Atitude crítica não significa opor-se imediatamente a informação apresentada, mas ter o discernimento de distinguir tal informação, resultando numa compreensão oriunda do pensamento crítico, o qual o sujeito inserido neste tempo da informação precisa desenvolver (Conceição \& Ghisleni, 2019, p. 10).

Neste período de pandemia, a educação brasileira e do mundo sofreu impactos provocados pela COVID-19, afetando diretamente o sistema de ensino, bem como, as metodologias e o processo de ensino e aprendizagem e consequentemente a formação continuada. A partir da divulgação do parecer técnico cientifico da Organização das Nações Unidas (OMS), em 11 de março de 2020, recomendando o distanciamento social, a fim de evitar a disseminação da doença, as instituições mantenedoras de educação repensaram as ações a serem implementadas para a continuidade do processo educativo nas escolas de todo país. Neste cenário de guerra, tivemos que nos reinventar e adequar às formas de trabalho coletivo para que pudéssemos alcançar os profissionais da rede municipal de ensino de Cuiabá.

A partir desse momento, os gestores estaduais e municipais criaram decretos com medidas emergenciais orientando os procedimentos a serem adotados em todos os setores da sociedade, para o enfrentamento da pandemia. Na rede municipal de educação, a principal medida adotada para a continuidade e desenvolvimento das atividades pedagógicas, foi não cessar as atividades escolares e a formação continuada.

Com o intento de fortalecer a prática pedagógica dos professores, a SME ofertou durante esse período atípico as instituições de ensino, cursos on-line, via ensino remoto. Neste cenário de caos, o professor teve que se adaptar para atender a demanda da turma. Sabemos que as dificuldades foram imensas e a falta de recursos tecnológicos de vários profissionais e principalmente a família dos estudantes tiveram também que se adequar ao novo normal. Foram realizadas oficinas em parceria com a Coordenadoria de Informática SME/CBA, acelerando a incorporação de tecnologia e inovação nas unidades educacionais, por meio de uma oferta balanceada de conexão à internet, conteúdos educacionais digitais e formação de professores.

Na proposta da Escola Cuiabana constam ações que envolvem Tecnologias da Informação e Comunicação (TICs) contempladas no percurso formativo dos docentes como, incentivo, ampliação e oferta para toda comunidade promovendo práticas e diferentes abordagens de ensino (Cuiabá, 2020, p. 268).

As formações continuadas seguiram as orientações estabelecidas pelo Ministério da Educação (MEC) com a Portaria $\mathrm{n}^{\circ} 343$ de 17 de março de 2020, que considerando as excepcionalidades advindas da pandemia dentro dos limites legislacionais, autorizou a substituição das disciplinas presenciais em andamento, por aulas que se utilizasse de instrumentos, meios digitais, tecnologias de informação e comunicação.

O trabalho de Assessoria de Formação da Secretaria Municipal de Educação, também sofreu alterações no formato e as atividades foram sendo reestruturadas, ocorrendo à necessidade de adaptação da formação continuada, que antes presencial 
e com oficinas, agora por meio de formações e orientações pelo uso das Tecnologias da Informação e Comunicação (TIC's). Momento que remeteu o sistema de ensino e seus participantes a repensar sobre as diversas formas da aplicação, utilização e alcance das tecnologias no ambiente educacional.

O distanciamento social afetou a prática educativa gerando enormes desafios e especificidades, uma busca da continuidade e viabilidade do ensino em todas as suas esferas, a sociedade em geral passa a fazer uso e tenta adaptar-se a instrumentos educacionais já conhecidos, como por exemplo, a Educação a Distância (EAD), ocorreu disparadamente a busca pelas TIC's, as quais acarretaram inúmeras discussões e formações acerca das concepções sobre ensino presencial físico, ensino remoto emergencial e ensino hibrido.

O uso Das TIC's no ambiente educacional não denota o abandono dos métodos existentes, mas sim a busca por novas abordagens que complementem e integrem às práticas de ensino, e sendo essas mudanças contínuas na cultura digital é necessário pesquisar sobre tais mudanças no processo de ensino e aprendizagem (Magalhães, Paiva \& Lima, 2021, p. 2).

Faz-se necessário pontuar que no Brasil, o Ensino a distância, já estava sendo realizado há anos e, com a proliferação do vírus, o qual ocasionou o colapso do sistema de saúde e inúmeras mortes, a EAD emerge como alternativa mais próxima das práticas adotadas na rede pública de ensino.

De acordo com o Conselho Nacional de Educação, nessa modalidade ocorre a mediação didático-pedagógica dos processos de ensino e aprendizagem, por meio de tecnologias envolvendo discentes, docentes, tutores e o desenvolvimento de atividades pedagógicas (Brasil, 2014, p. 19-20).

Beher (2020) conceitua o ensino remoto emergencial (ERE) como uma modalidade de ensino que pressupõe o distanciamento geográfico de professores e estudantes e foi adotado de forma temporária pelas instituições educacionais para que as atividades escolares não fossem interrompidas.

Aliado nessa concepção surge o ensino híbrido considerada uma abordagem pedagógica que combina atividades presenciais e atividades produzidas pelas Tecnologias digitais de informação e comunicação (TDICs) com foco no processo de aprendizagem discente mediada pelo professor (Valente, 2020, p. 6-7).

A pandemia enfatizou o reconhecimento das fragilidades e das potencialidades da comunidade educativa revelou de algum modo, as potencialidades e as fragilidades de nosso cotidiano, tanto em sua versão mais luminosa, como mais sombria (Castaman \& Rodrigues, 2020, p.19).

As ferramentas de ensino contribuem sobremaneira com as atuais metodologias utilizadas pelos educadores e acabaram provocando enormes discussões na sociedade como um todo, estudantes, família, gestores, formadores e professores que se viram diante de uma nova maneira de aprender e ensinar.

Diante da atual situação vivenciada pelos professores da rede municipal de ensino, temos a intenção de socializar a formação continuada do Programa de Melhoria da Proficiência (PROMP) ofertado aos profissionais da educação, considerando o novo normal que afetou diretamente o processo de ensino e aprendizagem nas unidades escolares, a gestão, considerando as orientações legais emanadas pelos órgãos competentes.

Em 2005, o Instituto de Estudos e Pesquisas Educacionais Anísio Teixeira (INEP) realizou a Prova Brasil. Uma avaliação para diagnóstico em larga escala, com objetivo de avaliar a qualidade do ensino a partir de testes padronizados e questionários socioeconômicos (INEP, 2007 p. 10). Os testes foram aplicados na quarta e oitava séries (atuais quinto e nono anos) do ensino fundamental, os estudantes respondem a itens (questões) de língua portuguesa, com foco em leitura, e matemática, com foco na resolução de problemas (INEP, 2007 p. 3).

O Ministério da Educação (MEC) em posse dos resultados obtidos na Prova Brasil, orientou as equipes gestoras e a sociedade em geral no sentido de mobilizar-se em busca de melhorias no ensino em todas as esferas educacionais. Assim, os resultados da Prova Brasil, serviram de base para o estudo "Aprova Brasil", que analisava o desempenho em leitura e 
matemática de estudantes da $4^{\mathrm{a}}$ e $8^{\mathrm{a}}$ séries $\left(5^{\circ}\right.$ ano e $9^{\circ}$ ano) do Ensino Fundamental de escolas públicas urbanas, na busca de fatores que possibilitaram a melhoria ou não desse desempenho (INEP, 2007, p. 8).

Os princípios do Aprova Brasil norteiam o direito à educação e o direito de aprender garantidos constitucionalmente a todas as crianças e adolescentes, com ênfase nas convicções da universalidade, progressividade, indivisibilidade e interdependência, exigibilidade e participação (INEP, 2007, p. 8). Essa constante defesa dos direitos perpassa pela necessidade de afirmação dentro da prática e realidade que toda a sociedade luta e almeja em prol do desenvolvimento humano.

Todos sem exceção têm direito à educação de qualidade, a escola é parte integrante do sistema de garantia desses direitos assegurando a aprendizagem, apoiada em uma gestão escolar democrática pela participação docente, funcionários, pais, estudantes, comunidade (INEP, 2007, p. 8).

O Programa PROMP, tema central deste artigo tem a finalidade de aperfeiçoar os conhecimentos necessários para melhoria nos resultados nas avaliações externas das escolas municipais de Cuiabá, referente à proficiência de Matemática identificando aspectos e fatores que possam contribuir para melhoria na aprendizagem. Tendo como parâmetro os princípios do Projeto Aprova Brasil, a SME desenvolveu o Programa de Melhoria da Proficiência (PROMP), com o objetivo de aperfeiçoar os conhecimentos específicos em Língua Portuguesa e Matemática na tentativa de melhorar esses resultados nas avaliações externas aplicadas nas escolas municipais de Cuiabá.

A proposta levou em consideração os estudos voltados para a didatização dos descritores da Prova Brasil dos $5^{\circ}$ e $9^{\circ}$ anos, com a possibilidade de fornecer recursos didáticos e alternativas aos professores regentes da turma, possibilitando redirecionar o planejamento e enriquecer a prática pedagógica em sala de aula.

\section{Metodologia}

Esta pesquisa tem abordagem qualitativa centrada na compreensão social partindo das interações e dos aspectos da realidade que não podem ser quantificados (Gerhardt \& Silveira, 2009, p. 31). O estudo baseou-se nas práticas formativas realizadas durante a formação continuada com os professores licenciados em pedagogia que ministram aulas para as turmas do $4^{\circ}$ ano do Ensino Fundamental. São profissionais unidocentes que participaram do Programa de Melhoria da Proficiência (PROMP) e lecionam aulas de Matemática na Rede Municipal de ensino de Cuiabá.

A metodologia pautou-se na descrição, sucintamente definida como uma forma de investigar a ação da prática adotada durante a formação continuada, sendo sistemática e empiricamente fundamentada com finalidade de aprimorar e contribuir com a prática docente (Gerhardt \& Silveira, 2009, p. 32).

Desta maneira a pesquisa vivenciada pelas autoras articula-se com a política da Escola Cuiabana/SME, especificamente ao que compete à formação continuada de professores, a relação teoria e prática e os ambientes exclusivos de formação.

A pesquisa foi realizada por quatro professoras da rede municipal de ensino de Cuiabá. Duas exercem a atividade diretamente em sala de aula, uma aposentou-se recentemente e a outra desenvolve a função na Coordenadoria de Formação, sendo responsável pela organização, seleção de estratégias, além de ministrar as formações de matemática aos pedagogos.

Pensado na diversidade das experiências partilhadas, o projeto denominado Programa de Melhoria da Proficiência (PROMP) em Matemática e Língua Portuguesa, foi elaborado e destinado à formação continuada, sendo ofertado aos professores e estudantes do $4^{\circ}$ ano do Ensino Fundamental das unidades escolares da rede municipal de Cuiabá.

O PROMP teve como objetivo contribuir para o aperfeiçoamento e a autonomia do docente na sua prática, propiciando o desenvolvimento do trabalho diferenciado nas áreas de Língua Portuguesa e Matemática fundamentada nos descritores da Prova SAEB (Sistema de Avaliação da Educação Básica), com foco na prática pedagógica, numa visão mais próxima da sala de aula, voltada especificamente para a aprendizagem de professores e estudantes do $4^{\circ}$ ano da Rede 
Municipal de Ensino.

\section{Resultados e Discussão}

O referido projeto foi sistematizado de acordo com a Política de Ensino da Escola Cuiabana, que destaca a importância da formação continuada, assim como o uso da tecnologia, como uma das competências gerais da Educação Básica. Coadunando com a BNCC que preconiza a utilização de tecnologias digitais, seja de comunicação ou informação, de forma crítica, significativa, reflexiva e ética nas diversas metodologias e práticas pedagógicas, na comunicação, acesso e disseminação de informações, gerando conhecimento e resolução de problemas.

A utilização das tecnologias tornou-se essencial durante o ano de 2020, considerando um momento de adaptações e mudanças. Os profissionais da educação tiveram que apropriar-se de habilidades antes não exploradas, sempre adiadas e muitas vezes renegadas. Viram-se obrigados a ceder, deixar a resistência de lado e aprender a lidar com as ferramentas tecnológicas para desenvolver o trabalho em sala de aula. Além do conhecimento das diferentes áreas e domínio da diversidade de conteúdo, tiveram que se reinventar para dar continuidade ao trabalho, repensar e reelaborar os planejamentos e se desdobrar para aprender e a conviver com o novo normal para ministrar aulas - o ensino remoto.

No primeiro momento, a formação continuada do PROMP foi organizada de forma que os encontros fossem realizados quinzenalmente, a partir do mês de março de 2020, porém com a publicação do Decreto Municipal $n^{\circ} 7.846$ de 18/03/2020, todas as atividades escolares presenciais e consequentemente, os encontros formativos foram suspensos nas unidades educacionais.

Entretanto, a reorganização da formação continuada na disciplina de Matemática do PROMP passou a ter como recurso principal, o uso de tecnologias acessíveis, levando em consideração que grande parte dos docentes já estivessem habituados a manuseá-las. Inicialmente optou-se pelo uso do WhatsApp, um aplicativo que conectado à rede de internet tornase uma multiplataforma de mensagens instantâneas, chamadas de voz para aparelhos smarthphones, envio de imagens, vídeos, arquivos. Criou-se um grupo, visando à comunicação mais próxima entre coordenadores escolares, professores e formadores, houve ainda a entrega de material didático, imagem na Figura 1, em forma de livros do PROMP aos estudantes, para que realizassem as atividades e também aos professores como auxílio durante o planejamento das aulas.

Figura 1: Livro do estudante Aprova Brasil $4^{\circ}$ Ano Matemática, 2020.

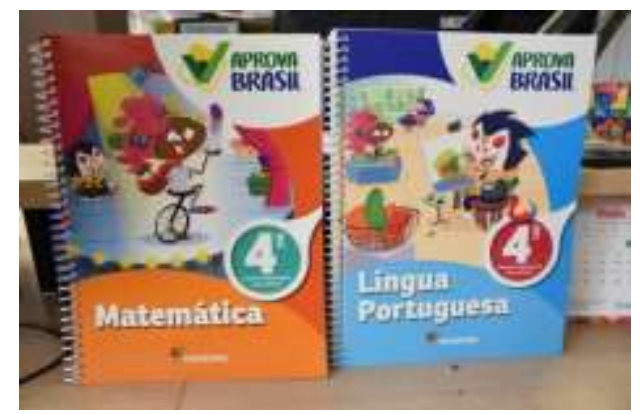

Fonte: Editora moderna.

O livro didático de matemática foi elaborado de forma contextualizada com ênfase em personagens, jogos e gabaritos para preenchimento dos simulados, com o intento de promover o manuseio do material didático, interação e a participação do estudante dos anos iniciais. Essa aproximação rompe as barreiras rígidas, inserindo o lúdico e os materiais concretos, considerados essenciais nessa etapa do desenvolvimento infantil. 
Alguns momentos formativos na disciplina de Matemática foram realizados por meio do serviço de comunicação por videochamadas o Google Meet, houve divisão de grupos de professores, por períodos e por regionais de localização das unidades escolares. Os encontros aconteciam em média por duas horas com reflexões, sugestões e questionamentos sobre o desempenho dos estudantes nas aulas e nos simulados realizados.

Nesse momento, foi possível verificar o avanço da ação docente, as trocas e partilhas de experiências, planejamentos, estratégias, encaminhamentos didáticos e das rotinas, sempre mantendo a relação entre teoria e prática, na Educação a Distância. Um momento ímpar de colaboração e trabalho coletivo que nos motivou a desenvolver este trabalho.

Para melhor compreensão e análise desse momento formativo, com a intenção de obter opiniões sobre os materiais e metodologias ofertadas, realizou-se entrevistas com duas professoras e duas coordenadoras cursistas do PROMP no ano de 2020, que pertenciam a duas unidades educacionais distintas, localizadas nos bairros das regionais, norte e leste da capital.

A professora Júlia, com formação no magistério e pedagogia, trabalha com os anos iniciais há mais de uma década na rede municipal e relata sobre o material didático:

Como aspecto positivo do trabalho com o projeto, a organização, o material didático, a plataforma e o material complementar, considero que foi de grande ajuda para o desenvolvimento dos descritores trabalhados com a turma (Entrevista concedida em março de 2021).

Outra depoente que contribuiu com a pesquisa, foi a professora Leticia do $4^{\circ}$ ano, também formada em pedagogia pela UFMT e leciona há quatro anos na rede municipal. Ao ser entrevistada destaca:

No início do projeto houve uma formação, um curso para ser feito no site e sendo sincera nem completei o curso. Estava meio perdida no início do projeto PROMP e acabei não concluindo. Ao longo do ano letivo houve os encontros de formação, após a realização de cada simulado. Ao todo, foram realizados 4 simulados e depois deles os encontros de formação, nos quais os professores podiam falar como foi o desenvolvimento das lições e do simulado com sua turma, era mais um espaço para troca de experiências sobre as devolutivas dos estudantes (Entrevista concedida em março de 2021).

As palavras retratam momentos de angústia, medo e desencontros, que a partir dos vários relatos, a equipe foi moldando e adaptando as oficinas para atender a demanda com a preocupação de não se distanciar da realidade inserida.

Neste percurso, o trabalho dos professores formadores foi realizado por meio de gravações de videoaulas que foram disponibilizadas a princípio, na rede de televisão aberta via canal da TV Mais, contratado pela SME/CBA que posteriormente foi suspenso pelas autoridades locais.

Posteriormente foi retomado o processo de formação e as videoaulas passaram a ser disponibilizadas via plataforma de compartilhamento de vídeo (YouTube) denominado como canal Portal da Escola Cuiabana. O YouTube é amplamente utilizado pelo público em geral, sendo popularmente acessível, mesmo existindo as versões paga e gratuita, logo a escolha dessa plataforma não geraria custos aos estudantes, professores e formadores. Os critérios de participação era que os discentes e professores tivessem acesso a rede de internet. As videoaulas da disciplina de matemática para os estudantes dos $4^{\circ}$ anos foram planejadas de acordo com os descritores da Prova Brasil, conforme aposta a Figura 2. 
Figura 2: Vídeoaula $4^{\circ}$ Ano - Matemática (PROMP) - Mais Multiplicação (Hab. $3^{\circ}$ Semestre).
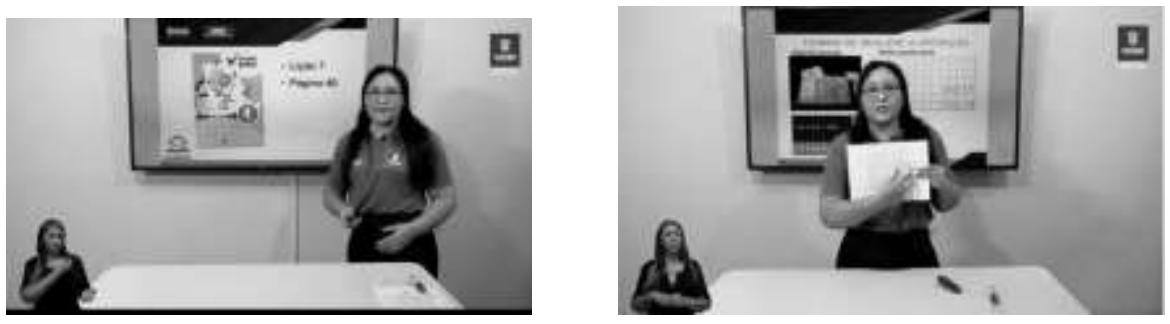

Fonte: Canal Portal da Escola Cuiabana (2020).

O canal do Portal da Escola Cuiabana (2020) na plataforma digital do Youtube tem em seu histórico virtual todas as videoaulas referentes às habilidades contidas no material didático e direcionadas para as avaliações externas que foram ministradas pelos professores formadores da SME na disciplina de Língua Portuguesa e Matemática.

Contribuindo para o processo formativo dos educadores, com foco nos resultados obtidos pelos simulados realizados com os estudantes, o site do Aprova Brasil destaca os resultados das avaliações aos coordenadores e professores participantes do PROMP que eram constantemente analisados. Outro recurso tecnológico disponibilizado foi o aplicativo de celular de leitura de códigos via Qr code, sendo possível o armazenamento de dados e acesso posterior. A esse respeito, a professora Letícia observa que:

Sim, eu gostei do material, ajuda muito. Além dos livros, no site também tinha material complementar para trabalhar esses descritores, bem organizado e com níveis de dificuldade diferentes, e no site a gente preenchia o gabarito e o sistema gerava os resultados, geralmente apresentavam a porcentagem de acertos das atividades e falavam um pouco sobre as habilidades que elas desenvolviam (Entrevista concedida em março de 2021).

Neste novo formato, torna-se essencial o uso das tecnologias digitais no ambiente escolar. As ferramentas auxiliam o professor não somente em sua formação, além de ampliar o conhecimento e expandir o contato entre os pares, estreitam os relacionamentos e a partilha de experiências entre os colegas de profissão. Essa troca de experiência possibilita uma visão mais significativa na construção do conhecimento, tornando-se autor e auxiliador na estruturação e autonomia dos educandos (Ferro et al, 2021).

Durante as formações síncronas, onde o ensino ocorre em tempo real, a aula é apresentada pelo professor e transmitida ao vivo por meio da plataforma escolhida. As videoaulas eram comentadas com os professores e algumas metodologias e reflexões eram realizadas ou sugeridas, visando o desenvolvimento dos discentes e a efetivação da transposição didática dos descritores de matemática.

Os conteúdos ministrados durante a formação de Matemática, (Números e Operações, Espaço e Forma, Grandezas e Medidas, Tratamento da Informação) para os estudantes do $4^{\circ}$ ano do Ensino Fundamental estabeleciam relações direta com os descritores da Prova Brasil, presentes na matriz de referência do SAEB.

Esses conteúdos possuem uma proposta didática exclusivamente ao desenvolvimento de habilidades, pautadas na resolução de situações-problemas e na compreensão de seus enunciados; estabelecer relações; validar processos; argumentar; raciocinar por meio de dedução, intuição, indução ou estimativa. Portanto, não havia pretensão de realizar uma sistematização dos conteúdos de matemática, mas conforme solicitação durante a formação, os professores deveriam utilizar esse material nas aulas regulares, como complemento ao material adotado durante o período de pandemia, que foram desenvolvidos e disseminados via grupo de mídia social da turma.

Outra depoente que contribuiu com a pesquisa foi a professora Jordana, pedagoga e efetiva da SME há mais de dez anos e atualmente exerce a função de coordenadora na unidade escolar da regional norte. Em relação ao Projeto PROMP e a 
formação continuada ofertada aos profissionais da educação, ela destaca:

O Projeto PROMP foi um ganho muito grande para os estudantes, pois o material foi elaborado com resultados concretos do nível de aprendizagem do $4^{\circ}$ Ano. Os materiais e as atividades foram pensados e elaborados nas dificuldades da aprendizagem dos estudantes, portanto o trabalho do professor ficou bem mais fácil, o desenvolvimento do professor o resultado só não foi melhor, porque as aulas estavam em modo remoto e nem todos os estudantes tiveram o acompanhamento necessário das famílias. A linguagem do material é de fácil entendimento e de grande contribuição no apoio pedagógico para os professores (Entrevista concedida em março de 2021).

O depoimento da professora aponta a real necessidade da formação continuada num período conturbado que momentaneamente os professores ficaram sem direcionamento. A fala retrata a contribuição do PROMP na disciplina de Matemática, configurando-se como um projeto de intervenção que auxiliou os professores na sua prática pedagógica em tempos de pandemia.

A professora Cláudia, formada em pedagogia e concursada 40 horas na rede municipal de ensino. Atualmente exerce a função de coordenadora pedagógica há mais de 5 anos na mesma unidade escolar, acompanha e monitora o desenvolvimento do curso, ressalta que:

É necessário fazer um aprofundamento, estudar sobre o projeto para depois colocá-lo em prática. Os cursos de aperfeiçoamento foram um tanto, quanto vagos, devido ao cenário que vivenciamos nesse ano (Entrevista concedida em março de 2021).

Especificamente sobre o livro didático de Matemática do PROMP, Jordana considera que:

O material voltado para a matemática foi significativo no desenvolvimento da aprendizagem dos estudantes, porque além de ter uma linguagem simples e direta, o material ainda vem com o material concreto e complementar como tabelas e jogos (Entrevista concedida em março de 2021).

E ainda acrescenta:

O projeto Aprova Brasil é tão importante na Língua Portuguesa quanto na Matemática, porque veio acrescentar e renovar o estudo não só para as avaliações externas, mas também para o cotidiano dos estudantes com atividades interessantes e inovadoras (Entrevista concedida em março de 2021).

Neste ínterim foram realizadas reuniões com os coordenadores das unidades escolares para repasse das informações e ações pedagógicas durante a formação na disciplina de Matemática. Na ocasião houve apresentação dos resultados obtidos sobre a correção dos simulados feitos pelos estudantes e alguns relatos de participação no projeto. Um contato mais próximo dos coordenadores foi possibilitado por meio do grupo de mídia social.

Em relação aos materiais disponibilizados durante o processo de formação continuada, a Coordenadora Cláudia elenca como considerações positivas:

O excelente material e contextualização dos objetos de conhecimento, e negativas o curto tempo de formação continuada para os professores (Entrevista concedida em março de 2021).

Ao retomarmos a entrevista com a professora Jordana ela destaca os pontos favoráveis durante a formação:

A linguagem simples e clara, as atividades complementares, o apoio pedagógico para os professores com todas as orientações necessárias, foco nas habilidades e aprendizagens não consolidadas para a fase da criança e como único ponto negativo que perceptível foi à falta de comprometimento de algumas famílias (Entrevista concedida em março de 2021). 
A professora Leticia também afirmou que:

Durante a realização do projeto as maiores dificuldades foram desenvolver as lições/habilidades que estavam programadas dentro do prazo determinado. $O$ projeto tinha um caráter bastante rígido quanto aos prazos de realização e devolutiva. Além disso, a adaptação para o trabalho remoto e as dificuldades apresentadas pelos estudantes também tornaram o trabalho mais difícil de ser realizado (Entrevista concedida em março de 2021).

Sobre o desenvolvimento e metodologia adotada durante a realização das aulas e atividades do curso de matemática a professora Leticia descreve:

Com a adaptação para o trabalho remoto, a interação com os estudantes foi por meio do grupo de WhatsApp da turma e também videochamadas no Google Meet. A cada semana era trabalhada uma lição do livro, o projeto também disponibilizava material complementar para trabalhar os descritores das lições do livro. Os áudios e vídeos explicativos de cada lição eram enviados no grupo da turma, a correção ocorria de modo individual por meio do WhatsApp e de modo coletivo por meio de chamada de vídeo no Google Meet, no qual também ocorria explicação das atividades da lição da semana, bem como, devolutiva dos simulados realizados (Entrevista concedida em março de 2021).

Quanto aos aspectos avaliativos e os resultados obtidos a professora Leticia ainda ressalta:

Os pontos fortes desse projeto são os suportes pedagógicos ofertados tanto pelo material didático quanto pela plataforma que permite o acompanhamento do desempenho de cada estudante ao decorrer de cada bloco de lições, assim facilitando o acompanhamento individual e coletivo. Em contraponto há aspectos que precisam ser melhorados como um cronograma mais flexível para realização das lições e uma formação com enfoque mais específico nos pós simulados com possibilidades de intervenções que nos auxiliem a sanar as dificuldades apresentadas pelos estudantes (Entrevista concedida em março de 2021).

Os relatos evidenciam a importância de unir o corpo docente e toda estrutura de ensino, envidando esforços na adequação das ferramentas educacionais para um melhor proveito da educação escolar, adaptando-se assim na implantação da tecnologia digital (Ferro et al, 2021).

Os estudos foram feitos na expectativa de relacionar a teoria e prática durante a pandemia, retomando a experiência de formação continuada com o grupo de professores em efetivo exercício docente e participantes do projeto. O período será marcado e até diríamos inesquecível pelo momento atípico que ainda vivenciamos. Será lembrado como tempos difíceis, um momento de luto, tristeza e constantemente pela reflexão do papel do professor e a sua prática docente, visto que as novas tecnologias tiveram que ser diariamente utilizadas por grande parte dos professores e estudantes.

Nesse contexto a formação de professores é vista como um processo gradual, que requer tempo, investimento pessoal, profissional revendo crenças e resistências, oportunizando ambiências tecnológicas e espaços de socialização de experiências didáticas, para promover uma mudança contínua na percepção e para construção de práticas mais modernas e inovadoras (Veloso \& Briccia, 2021, p. 5-6).

Segundo Schön (2000, p. 34) a "reflexão-na-ação" e "a imediata significação para ação" procura instigar o professor na interação da teoria e prática, no processo de ensino fundamentado na intenção de "aprender a aprender" e sempre refletir sobre sua atuação.

Possibilitar uma formação continuada que integre saberes e visualize os impactos diretos da pandemia na realidade educacional, bem como, as consequências da quarentena, do distanciamento social na vida desses profissionais, como traumas de natureza psicológica, mental, econômica, acompanhando-os para que não interfira na qualidade do processo ensino e aprendizagem (Pinto, Venturin \& Costa, 2020, p. 12-13). 


\subsection{As oficinas de Matemática}

No ano de 2019 acontece a primeira oferta da formação do PROMP realizada com os professores que trabalhavam com as turmas do $5^{\circ}$ ano do Ensino Fundamental. O critério de seleção do $5^{\circ}$ ano justifica-se pela necessidade de melhoria nos resultados da avaliação externa da Rede Municipal de Educação de Cuiabá, considerando que nesse ano haveria a Prova Brasil e as turmas seriam avaliadas.

Dessa forma, a metodologia adotada para o curso baseou-se nas concepções expostas na BNCC e principalmente nos descritores da Matriz de Referência da Prova SAEB. O curso com carga horária de 70 horas foi dividido em momentos presenciais e não presenciais. Em 2019, nos encontros presenciais os formadores realizaram oficinas com fundamentação teórica e atividades práticas, onde foram trabalhados os descritores da Prova Brasil com sua aplicação e sugestões para os professores ministrarem durante as aulas.

Durante a oficina, os conteúdos abrangiam os quatro eixos: Números e Operações; Espaço e Forma; Grandezas e Medidas e Tratamento da Informação na disciplina de matemática foram trabalhados com os professores e, além da leitura para se apropriar dos conceitos matemáticos, desenvolviam na prática as atividades para aplicar aos estudantes.

O conteúdo Números e Operações foram explorados por meio da contextualização e dos conceitos teóricos. Os procedimentos matemáticos expostos em slides, seguido da prática com a resolução de problemas fazendo o uso de materiais concretos, ferramentas digitais e jogos matemáticos.

Os professores cursistas aplicavam esses procedimentos em sala de aula, e posteriormente durante as oficinas relatavam e apresentavam estratégias e recursos utilizados no desenvolvimento das aulas aos demais cursistas, por meio de imagens ou vídeos.

Todos os conteúdos eram instigados a promover reflexão dos conceitos teóricos abordados, com ênfase na importância dos procedimentos utilizados durante o desenvolvimento de cada conteúdo. Por exemplo, durante o processo de ensino do eixo Espaço e Forma, uma das oficinas contemplou a construção do percurso da sala, com a localização espacial e objetos do próprio aluno.

Na explanação do eixo de Grandezas e Medidas, desenvolveu-se a construção de um relógio e a realização de procedimentos para leitura das horas, estabelecendo relação do relógio com o calendário para os registros.

No eixo Tratamento da Informação, a oficina foi realizada com a construção de tabelas e gráficos, tendo como principal estratégia, a tabela dos aniversariantes da turma, tipos de frutas preferidas, dentre outras atividades.

Outro aspecto importante do curso foi aplicação dos simulados com o uso dos descritores vinculados aos eixos em destaque para avaliar a aprendizagem dos estudantes.

No ano de 2020 com a pandemia, tornou-se necessário as adequações metodológicas e adotou-se como orientações destinadas aos professores, o uso do aplicativo via grupo de WhatsApp, encontros virtuais no Google Meet para estudo dos descritores e análise dos simulados realizados com os estudantes. Neste período também foi adotado o livro didático para o estudante e o guia para o professor que dividia os descritores em lições como destaca a Figura 3. 
Figura 3: Guia do Professor Aprova Brasil 4 Ano - Matemática, 2020.

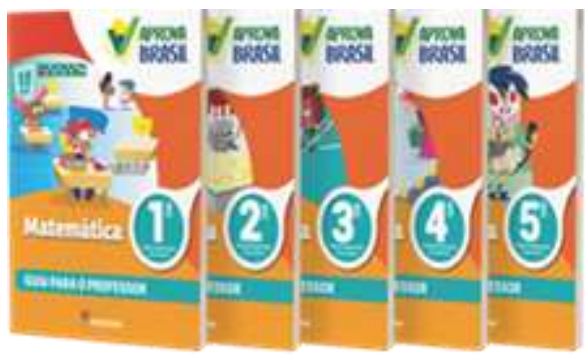

Fonte: Editora moderna.

Após o estudo de cinco lições era realizado os simulados com os estudantes, perfazendo o total de 4 simulados durante o ano letivo. Os formadores ainda realizaram orientações e ministraram aulas, via canal do YouTube auxiliando-os na aplicação e desenvolvimento dos conteúdos trabalhados.

\section{Considerações Finais}

O relato de experiência constituiu-se por meio da formação continuada (PROMP) realizada pela Secretaria Municipal de Educação de Cuiabá (SME) ofertada aos professores da rede de ensino na disciplina de Matemática. É possível inferir que o ano letivo de 2020 foi desafiador, principalmente aos professores e estudantes que precisaram se adaptar rapidamente a nova forma de oferta de ensino, envolvendo o uso de novas tecnologias e as ferramentas digitais para o desenvolvimento das aulas.

É preciso pontuar também como desafio, as questões de adaptações sociais, dificuldades financeiras e utilização e aquisição das mídias a serem usadas no ensino remoto. Neste processo de ensinar e aprender, a família, estudantes e profissionais da educação permanecem sendo expostos e desafiados tanto nos aspectos cognitivos como sócio emocionais.

Logo, foi possível observar dificuldades na prática docente nesse contexto de pandemia, alguns professores afirmaram não possuir formação ou habilidades básicas para inserir e utilizar as TIC's durante as aulas, ou seja, sendo necessário repensar a formação continuada voltada para o uso efetivo das tecnologias educacionais.

Durante as formações do PROMP na disciplina de Matemática ficaram evidenciadas que muitos professores demonstraram ter domínio pedagógico, curricular e dos conceitos a serem mediados com os estudantes, entretanto, transpor para a prática via meio digital com o uso das ferramentas digitais, demonstraram insegurança no manuseio, envio de arquivos e até mesmo, comunicar-se pelo aplicativo Google Meet, sendo necessário, constantes orientações e auxílio aos professores, que por sua vez, atenderam o estudante e seu responsável para a realização das atividades e avaliações nos ambientes virtuais.

A formação do PROMP na disciplina de Matemática foi essencial para cumprimento dos anseios quanto à melhoria da qualidade da educação e continuidade da formação de professores neste período de enfrentamento ao vírus, isolamento social, repleto de inseguranças e angústias.

Observa-se que os efeitos causados pela pandemia provavelmente modificarão muitos hábitos, culturas e metodologias, desta forma, o ensino por meio das TIC's, se fará cada vez mais presente na prática pedagógica dos profissionais, como instrumento, suporte ou complemento ao exercício docente devendo ser constantemente analisado, considerando que esses recursos estejam ao alcance do professor e do estudante, acessíveis e possibilitem o desenvolvimento pleno dos estudantes.

Dessa forma, o trabalho da formação continuada com os professores deve ser repensado e reorganizado, deixando de lado o sistema engessado para implementar as novas tecnologias e métodos que contribuam para a atuação efetiva do professor na sua prática. Outro fator importante refere-se aos estudantes e principalmente aos gestores que precisam elaborar políticas públicas de incentivo, acesso e inclusão das TIC's e atendam às necessidades educacionais, que diante deste cenário de caos, 
demonstrou com clareza o abismo ainda existente no sistema público de ensino do país, onde as minorias continuam sendo excluídas como um princípio estabelecido como um direito básico e fundamental.

A partir da análise dos materiais pesquisados, olhar sob diferentes perspectivas os dados coletados durante as entrevistas e observação do material didático dos cursos propiciou enxergar a subjetividade presente na fala dos participantes, que certamente não poderiam ser evidenciados com base apenas no material didático.

Não tivemos a pretensão de esgotar as análises das fontes, apenas vislumbrar perspectivas e possíveis leituras de um determinado contexto histórico relacionado à formação continuada de professores. Fica evidente que a formação de professores em tempos de pandemia merece um estudo mais aprofundado, considerando que produção de conhecimento não se dá unicamente pelo aspecto pontual e exclusivista da percepção aqui apresentada, mas, pela ampliação a partir de novos olhares e interpretações sobre um dado momento histórico.

\section{Referências}

Aranha, M. L. (1996). A. Brasil no Século XX: o desafio da educação. História da Educação. Moderna.

Brasil. (2017). Base Nacional Comum Curricular. Mec/Consed/Undime.

Brasil. (1988). Constituição da República Federativa do Brasil. Centro Gráfico.

Brasil. (1996). Lei nº 9.394, de 20 de dezembro de 1996. (1996). Estabelece as Diretrizes e Bases da Educação Nacional. Diário Oficial da União, seção 1.

Brasil. (2014). Lei no 13.005, de 25 de junho de 2014 do Plano Nacional de Educação. Brasília: Diário Oficial da República Federativa do Brasil, Brasília, 26 jun. 2014b. Seção 1, p. 1.

Brasil. (2020). Portaria $n^{\text {o }} 343$, de 17 de março de 2020. Dispões sobre a substituição das aulas presenciais por aulas em meios digitais. Ministério da Educação.http://www.in.gov.br/en/web/dou/-/portaria-n-343-de-17-de-marco-de-2020-248564376

Beher, P. A. (2020). O Ensino Remoto Emergencial e a Educação a Distância. https://www.ufrgs.br/coronavirus/base/artigo-o-ensino-remoto-emergencial-ea-educacao-a-distancia/

Castaman, A. S., \& Rodrigues, R. A. (2020). Educação a Distância na crise COVID - 19: um relato de experiência. Research, Society and Development, 9(6), e180963699. https://doi.org/10.33448/rsd-v9i6.3699

Conceição, E. F. V. \& Ghisleni, T. S. (2019). Era digital: letramento (s) digital (is). Research, Society and Development. https://rsdjournal.org/index.php/rsd/article/view/1785/1374

Cuiabá. (2020). Decreto $n^{\circ} 7846$ de 18/03/2020.Dispõe sobre medidas temporárias, emergenciais e complementares ao Decreto $\mathrm{n}^{\circ} 7.839$, de 16 de março de 2020, de prevenção de contágio pelo novo Coronavírus (COVID-19), no âmbito do município de Cuiabá, e dá outras providências. https://www.cuiaba.mt.gov.br/download.php?id=109462. Cuiabá.

Cuiabá. (2020). Escola Cuiabana: cultura, tempos de vida, direitos de aprendizagem e inclusão. Editora Gráfica Print.

Cuiabá. (1999). Escola Sarã: Um novo contexto político-pedagógico para as escolas municipais de Cuiabá. Secretaria Municipal de Educação. DEP/SME, Cuiabá.

Cuiabana, C. (2020). Portal da Escola Cuiabana PROMP Matemática $4^{\circ}$ Ano. https://www.youtube.com/watch?v=6NQwEp7TRW0

Ferro, D. B. et al. (2021). Formação do professor no ensino da Matemática em tempos de isolamento social no ensino híbrido: uma revisão sistemática. Research, Society and Development. https://rsdjournal.org/index.php/rsd/article/view/15162/13577

Freire, P. (1987). Pedagogia do Oprimido. (41a ed.), Paz e Terra.

Gerhardt, T. E., \& Silveira, D. T. (2009). Métodos de Pesquisa. Curso de Graduação Tecnológica, Planejamento e Gestão para o Desenvolvimento Rural da SEAD/UFRGS. Editora da UFRGS.

INEP. (2007). Aprova Brasil: o direito de aprender: boas práticas em escolas públicas avaliadas pela Prova Brasil. Brasília. https://crianca.mppr.mp.br/arquivos/File/publi/mec/aprova_brasil.pdf. Acesso em: 11 mar. 2021.

Magalhães, J. H. de S., Paiva, L. I., \& Lima, S. de P. (2021). Instagram como ferramenta educacional na formação de professores de língua estrangeira. Research, Society and Development, 10(3), e42810313445. https://doi.org/10.33448/rsd-v10i3.13445.

Mato, G. (2001). Escola Ciclada em Mato Grosso: Novos tempos e espaços para ensinar - Aprender a sentir, ser e fazer. Secretaria de Estado de Educação (Seduc). Cuiabá.

Moderna, S. (2020). Aprova Brasil: mais que um material. https://www.solucoesmoderna.com.br/produtos-de-educacao/aprovabrasil/?gclid=Cj0KCQjw4v2EBhCtARIsACan3nzATfda9JVMGYWCKHmHD250eUEfCnruESHw14Zr1lmgYdyuizdXeygaAsIrEALw_wcB 
Research, Society and Development, v. 10, n. 7, e8710716328, 2021

(CC BY 4.0) | ISSN 2525-3409 | DOI: http://dx.doi.org/10.33448/rsd-v10i7.16328

Pereira, A. S., Shitsuka, D. M., Parreira, F. J., Shitsuka, R. (2018). Metodologia da Pesquisa Cientifica. Núcleo de Tecnologia Educacional da Universidade Federal de Santa Maria. Rio Grande do Sul.

Pinto, J., Venturin, C., \& Costa, L. (2020). A formação continuada do (a) professor (a) em meio a pandemia do Covid-19. Revista de Administração Educacional, 11(1), 5-19. https://doi.org/10.51359/2359-1382.2020.246465

Saviani, D. (2009). Formação de professores: aspectos históricos e teóricos do problema no contexto brasileiro. Revista Brasileira de Educação, Campinas, vol.14, n. 40 .

Schön, D. A. (2000). Educando o profissional reflexivo. Artmed.

Valente, J. A., \& Almeida, M. E. B. (2020). Políticas de tecnologia na educação no Brasil: Visão histórica e lições aprendidas. Arquivos Analíticos de Políticas Educativas. Revista Acadêmica, 28(94).

Veloso, A. M. F., \& Briccia, V. (2021). O professor remoto: a reinvenção da prática pela fluência digital. Research, Society and Development, 10(2), e3810212138. https://doi.org/10.33448/rsd-v10i2.12138. 